NBER WORKING PAPER SERIES

PRICES DURING THE GREAT DEPRESSION: WAS THE DEFLATION OF 1930-32 REALLY UNANTICIPATED?

Stephen G. Cecchetti

Working Paper No. 3174

NATIONAL BUREAU OF ECONOMIC RESEARCH

1050 Massachusetts Avenue

Cambridge, MA 02138

November 1989

Thanks are due to Laurence Ball, Robert Barsky, Ben Bernanke, Michael Bordo, Robert Cumby, Paul Evans, James Hamilton, Nelson Mark, Frederic Mishkin, Peter Temin, Paul Wachtel and seminar participants at the University of South Carolina and at the NBER Workshop on Macroeconomic History for comments and helpful discussions; to Jeff Miron for providing his data; and to John Campbell for sharing his computer software. Support of the National Science Foundation Grant No. SES-8821796 is gratefully acknowledged. All of the data and programs used for this paper are available upon request. This paper is part of NBER's research program in Financial Markets and Monetary Economics. Any opinions expressed are those of the author not those of the National Bureau of Economic Research. 
NBER Working Paper \#3174

November 1989

\section{PRICES DURING THE GREAT DEPRESSION: WAS THE DEFLATION OF 1930-32 REALLY} UNANT ICIPATED?

\section{ABSTRACT}

Several explanations for the depth of the Great Depression presume that the $-30 \%$ deflation of 1930-32 was unanticipated. For example, the debt-deflation hypothesis originally put forth by Irving Fisher is based on the notion that unanticipated deflation increases the burden of nominal debt, adversely affecting the banking system and the aggregate economy. Other theories imply on ex ante real interest rates being low during the period, and so it is essential that the deflation was unanticipated.

This paper measures inflationary expectations from data on prices, interest rates and money growth in order to investigate whether the deflation could have been anticipated. Current econometric techniques are used to compute expectations implied both by the univariate time series properties of the price level, and by the information contained in nominal interest rates. The major conclusion is that price changes were substantially serially correlated, and so once the deflation began, people expected it to continue. This implies both that the deflation was anticipated, and that real interest rates were very high during the initial phases of the Great Depression. These results call into question the validity of theories that rely on contemporary agents' belief in reflation during the early 1930s, and provide further support for the proposition that monetary contraction was the driving force behind the economic decline.

Stephen G. Cecchetti

NBER and Ohio State University

Department of Economics

1945 North High Street

Columbus, OH 43210-1172 


\section{Introduction}

In 1933, Irving Fisher (1933) published a paper entitled 'The Debt-Deflation Theory of the Great Depression.' He hypothesized that the nearly $25 \%$ cumulative deflation of 1930-32 was primarily responsible for the depth of the Depression. The argument proceeds as follows. Since unanticipated deflation increases the burden of nominal debt, it caused debtors to default on loans. This, in turn, led to bank failures and the collapse of the financial system.

Recently, Bernanke and Gertler (1987 and 1989) have formalized one aspect of the debtdeflation hypothesis. They examine a model in which a debt-deflation lowers borrower net worth, thereby increasing leverage and the desire of entrepreneurs to take on risk, and raising the probability of bankruptcy. This lowers the of level investment, causing a reduction in both aggregate supply and aggregate demand.

The debt-deflation theory requires both that there be substantial nominal debt outstanding, and that the deflation of $1930-32$ be unanticipated. This paper investigates the second of these by examining whether the deflation of early 1930s, when prices fell at an average of $-6.7 \%$ per year for three years, might have been anticipated. Data on both prices and interest rates provide empirical support for the proposition that the deflation could have been anticipated at horizons of three to six months. This calls into question theories of the Depression that rely on contemporary agents' belief in reflation prior to 1933.

A number of pieces of evidence suggest this conclusion. First, deflation was within the recent experience of the people living in 1929. In fact, in the fifty or so years between the Civil War and the Great Depression, there were four episodes in which the price level fell for two consecutive years or more. Second, inflation was very persistent during the interWar years. This suggests that simple rules of thumb would have led to the expectation of continued deflation during the period. Finally, the information contained in interest rate data can be used to extract estimates of both ex ante real interest rates and expected inflation. While nominal interest rates were low, the data suggest that beginning as early as 1927 and going through early 1933, real interest rates were very high. This leads to the conclusion that individuals of the time period perceived that prices were falling, and expected the deflation to continue.

While the primary purpose of this paper is to present evidence consistent with the notion that the deflation of the 1930s could have been anticipated, the empirical results can also be 
used to address other outstanding issues as well. In the process of generating estimates of anticipated price changes, I am able to produce estimates of the real rate of interest during the period from 1919 to 1940 . These estimates show that real interest rates were high throughout the period from 1929 trough 1932. This provides further support for the position of Friedman and Schwartz (1963) in their debate with Temin (1976). As Schwartz (1980) points out, a high real interest rate is one of the key features that distinguishes the monetary hypothesis from theories based on exogenous declines in real consumption or investment.

The approach of this paper is to use contemporary econometric tools to examine data on prices, interest rates and money in order to measure implied expectations. Three separate types of evidence are brought to bear on the question. First, Section 2 describes the history of past deflations. This is followed by a study of the univariate time series properties of the price level in Section 3. Included are unit root tests, identification and estimation of ARMA models, and a discussion of the properties of the forecasts implied by the estimated models. Section 4 describes a method for estimating expected inflation from interest rate data. In all cases, the conclusion is that the deflation was anticipated at horizons of three to six months.

These results challenge those of previous work, particularly that of Hamilton (1987) who measures inflationary expectations from data on commodity futures prices. Section 5 contrasts the methods used here with those used by Hamilton to assess the relative validity of the different techniques. The final section contains concluding remarks and suggests directions for future research.

\section{The History of Previous Deflations}

While a sustained, broad decline in nominal prices would take virtually everyone by surprise if it happened today, this was not true in 1930. Deflation was clearly within the experience of contemporary economic agents. This point is made clear by Table 1, where information is presented on the deflations of the late 19 th and early 20 th century. Data sources are described in the appendix.

Between the Civil War and the Great Depression, there were four periods of sustained deflation, when consumer prices fell for two consecutive years or more. The 1920-22 deflation following World War I was clearly the most severe. In fact, the cumulative price 
Table 1: Deflations from 1869 to 1932

\begin{tabular}{cccccc}
$\begin{array}{c}\text { Length of } \\
\text { Deflation }\end{array}$ & 5 yrs. & 3 yrs. & 2 yrs. & 2 yrs. & 3 yrs. \\
\hline $\begin{array}{c}\text { Consumer } \\
\text { Price Index }\end{array}$ & $-12.3 \%$ & $-13.8 \%$ & $-3.6 \%$ & $-17.8 \%$ & $-27.9 \%$ \\
$\begin{array}{c}\text { Wholesale } \\
\text { Price Index }\end{array}$ & $-22.1 \%$ & $-15.8 \%$ & $-8.2 \%$ & $-37.8 \%$ & $-31.6 \%$ \\
$\begin{array}{c}\text { GNP } \\
\text { Deflator }\end{array}$ & $-12.9 \%$ & -12.2 & $-4.2 \%$ & $-19.4 \%$ & -23.3 \\
$\begin{array}{c}\text { Cumulative } \\
\text { Real GNP } \\
\text { Growth }\end{array}$ & $+22.4 \%$ & $+5.0 \%$ & $-3.1 \%$ & $+3.4 \%$ & $-29.2 \%$ \\
\hline
\end{tabular}

Data sources are described in the Appendix.

decline during these two years was roughly the same as the decline during the early 1930s.

Given this history of deflations, people must have been aware of the possibility of price declines and had experience coping with them. In light of that experience, the subjective probability assigned to the occurrence of such an event could have been fairly high. It is unreasonable to presume that the 1930-32 deflation caught people completely off guard.

\section{The Time Series Properties of the Price Level}

\subsection{Overview}

The first step in examining the data on inflation is to study the univariate properties of the consumer prices. The major purpose of this section is to examine ARMA forecasts of inflation for the 1930-32 period. The conclusion is that there was substantial persistence in the inflation in the 1920's, and so it is reasonable to believe that once it started, deflation was anticipated to continue.

It is useful to begin with a simple plot of the data on level of consumer prices, monthly from 1913 to $1940 .^{1}$ Figure 1 plots the natural logarithm of the index. The figure includes

\footnotetext{
'As described in the appendix, the data on consumer prices is mainly the cost of living index (CLI)
} 


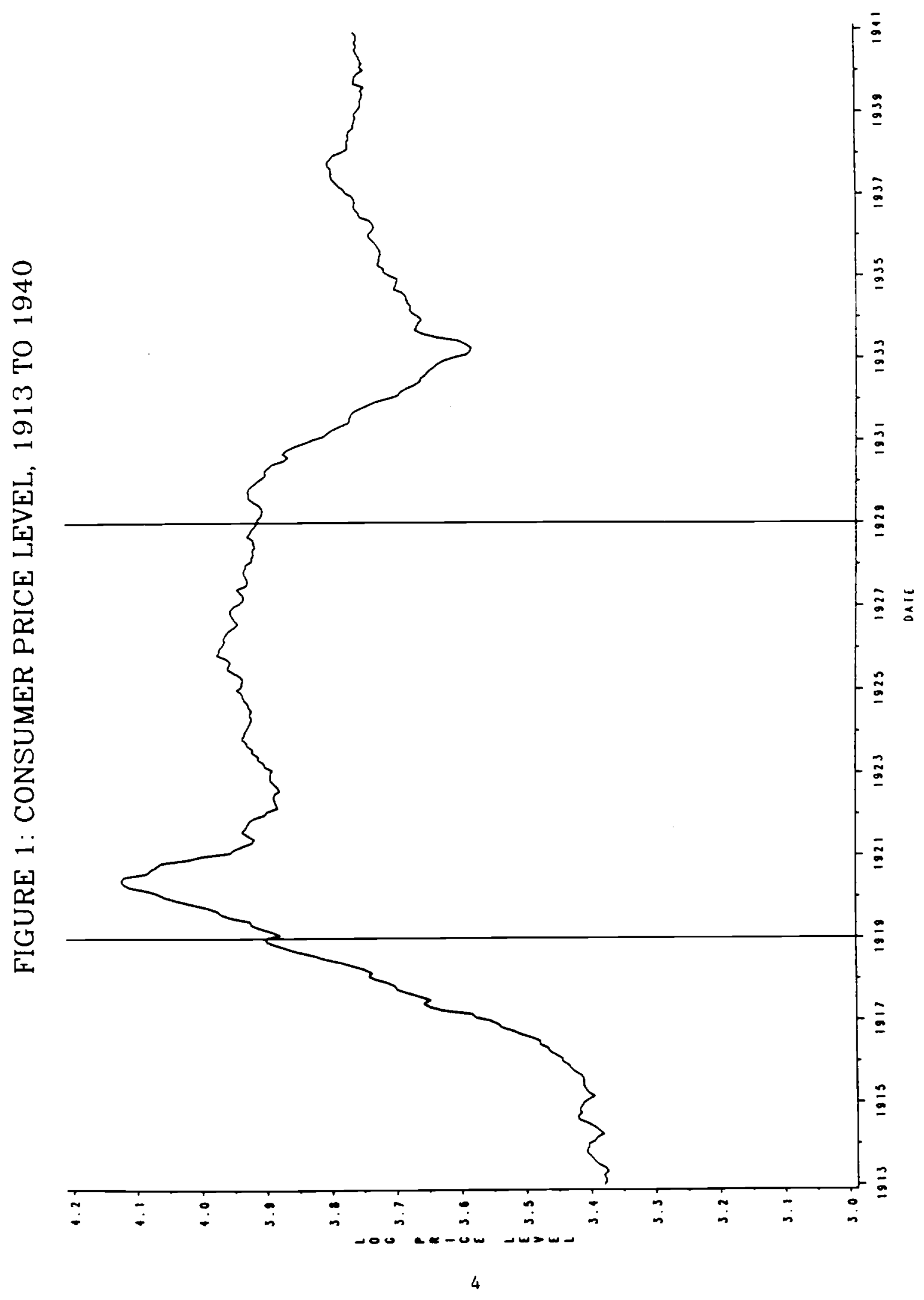


vertical lines drawn at the beginning of 1919 and the beginning of 1929, the period which will be examined more closely below. The data clearly show a pattern that is inconsistent with a stationary time series. The plot shows that prices did not revert to any sort of absolute level or deterministic trend. Instead, the pattern is that of a nonstationary series. ${ }^{2}$

The remainder of this section begins with a series of preliminary steps and then reports the results of a univariate ARMA forecasting exercise. Section 3.2 establishes the plausibility of assuming that the log of the price level is a first order integrated process, implying that inflation is a stationary series. This is done by examining both empirical evidence based on the data plotted in Figure 1, and theoretical arguments in favor of the unit root hypothesis.

The following section presents the results of a simple exercise to determine the univariate ARMA process for inflation. Using quarterly data from 1919 to 1928 only, inflation is modeled by an MA(2). When data through 1940 is added to the sample period, the resulting identification is that inflation follows an $A R(1)$. Both of these processes imply persistence.

Finally, results on univariate forecasts of inflation are presented using both $M A(2)$ and the AR(1) model, along with the forecasts implied by the models. The forecasts clearly suggest that the deflation of $1930-32$ was anticipated.

\subsection{Unit Roots: Theoretical Arguments and Empirical Tests}

The first step in estimating ARMA models is to examine whether the price level contains a unit root. There are both theoretical and empirical reasons for believing that the price level is nonstationary. It is well recognized that in the presence of a paper money standard, inflation is tied to the level of money growth, which is normally presumed to be an exogenous policy variable. The conclusion is that the price level is nonstationary. In fact, the data on the post-WWII period suggest that it is the second difference of the price level that is stationary with the current institutional arrangement. ${ }^{3}$

It is less clear what the time series properties of the price level should be in the presence of a gold or commodity money standard. But the same reasoning that leads one to suspect

constructed from monthly surveys by the National Industrial Conference Board. These data are based on contemporaneous monthly surveys and were made available through publications of the period. Prior to 1919, the consumer price data is drawn from the current Bureau of Labor Statistic Consumer Price Index series (CPI). The CLI series is preferred to the CPI, since the later appears to have been constructed by interpolating data at a frequency of approximately six months.

${ }^{2}$ The wholesale price series, which is also used in the following analysis, has the same broad profile.

${ }^{3}$ Barsky (1987) identifies inflation as an IMA(1,1) using quarterly data from 1960 to 1979. 
that the price level is nonstationary when there is fiat money, holds when a gold standard is operating. In fact, the price level would be stationary only by chance.

The argument follows directly from the equation of exchange, which can be manipulated to yield

$$
\Delta \log P_{t}=\Delta \log M_{t}+\Delta \log V_{t}-\Delta \log Y_{t} .
$$

where $M$ is the stock of money, $V$ is velocity, $P$ is the price level, and $Y$ is real output. Under a gold standard, the money stock $M$ is a roughly constant multiple of the size of the monetary gold stock. ${ }^{4}$ Equation (1) implies that velocity, money, output and the price level will be cointegrated. This means that $\log P_{t}$ will be stationary only if the three variables on the right hand side are either all stationary, or are cointegrated with cointegrating vector equal to $(1,1,-1)$. Put another way, the simple quantity theory implies that, unless the rate of growth of the gold stock happens to match the rate of growth of real output, or velocity happens to be growing to exactly offset the difference between the base money and output growth rates, the price level will contain a unit root. Using a similar argument, Bordo and Ellson (1985) demonstrate that as a result of resource constraints and in the presence of depletion, one should actually expect long-run deflation under a classical gold standard. ${ }^{5}$

The natural next step is to see whether the unit root hypothesis is confirmed by statistical tests. Dickey and Fuller (1981) have proposed a test based on examining the coefficient on the lagged price level in the regression given by

$$
\Delta p_{t}=a+b p_{t-1} \sum_{i=1}^{k} c_{i} \Delta p_{t-i}+v_{t}
$$

where $p$ is the $\log$ of the price level, $\Delta p$ is the first difference in the log of the price (inflation), $v$ is a random error, and the remaining terms are parameters. The null hypothesis is that the $\log$ of the price level $\left(p_{t}\right)$ has a unit root, namely that $b=0$. The test requires the

\footnotetext{
"As described in equation (1) of Bordo and Ellson (1985), the stock of money is equal to the product of the value of monetary gold stock, the fixed nominal price of gold, and a multiplier relating the sum of currency and deposits to the value of the monetary gold stock.

${ }^{3}$ Bordo and Ellson's conclusion suggests that deflation should have been the long run tendency throughout the 1920s. This means that each year that passes without deflation should increase the probability of deflation in the near-term future. Since prices actually rose from 1919 to 1928, Bordo and Ellson's reasoning suggests that by 1929 agents should have assigned a significant probability to price level declines.
} 
Table 2: Dickey-Fuller Tests for a Unit Root

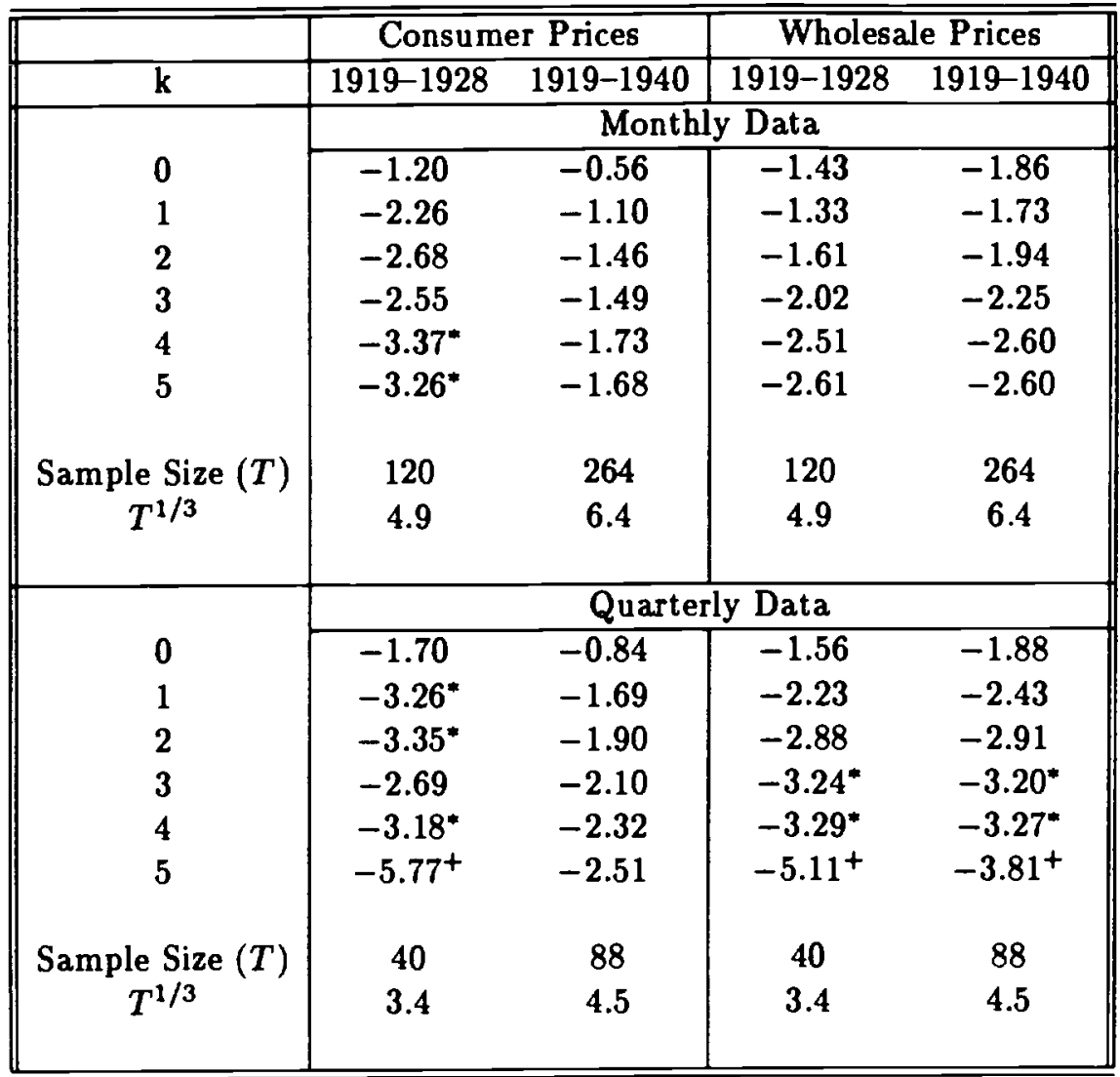

Test statistics are $t$-statistics on $b$ in equation (1). A ' $*$ ' signifies rejection at the $10 \%$ level, while $a$ ' + ' signifies rejection at the $5 \%$ level.

Significance levels are from Fuller (1976) Table 8.5.2 pg. 373.

choice of $k$, the number of autoregressive lags in the first difference to include. ${ }^{6}$

Table 2 reports the results of the Dickey-Fuller test using both consumer and wholesale price data over different sample periods at both monthly and quarterly frequencies, for values of $k$ from 0 to $5 .^{7}$ When the full sample is used the only evidence against a unit

\footnotetext{
${ }^{6}$ While the Dickey-Fuller test has enjoyed widespread use, Schwert (1988) has shown that it has substantial size distortion and low power when the true model contains an autoregressive component along with the unit zoot. Schwert's Monte Carlo experiments suggest that size distortion is minimized when $k$ is chosen to be roughly the cube root of the sample size - the suggestion made by Said and Dickey (1985).

${ }^{7}$ The Wholesale price data is the official BLS all commodities PPI, which was collected and published monthly during the period. Quarterly data is constructed by taking the last monthly observation of each
} 
root comes from the quarterly WPI. Otherwise, all of the values of the test statistic are well below the $10 \%$ critical value. Using the shorter sample, from 1919 to 1928 , the picture is slightly different. For the monthly WPI, the tests all fail to reject the unit root null. But for consumer prices, and for the quarterly WPI, this is no longer the case. For monthly consumer price data, the unit root null is rejected at the $10 \%$ level when $k$ equals 4 or 5 . For the quarterly consumer data, the unit root null is rejected at the $10 \%$ level when $k$ equals 1,2 , or 4 and at the $5 \%$ level when $k$ equals 5 . Finally, for quarterly WPI data, the unit root is rejected at the $10 \%$ level when $k$ equals 4 and at the $5 \%$ level when $k$ equals 5 .

While the results from the Dickey-Fuller tests are somewhat inconclusive, the majority of the evidence fails to reject the existence of a unit root in the price level. Together with the theoretical arguments, this strongly suggests studying the implications of assuming that inflation is the stationary series. The following section, proceeds by examining ARMA models of inflation. ${ }^{8}$

\subsection{ARMA Models: Identification, Estimation and Forecasting}

The next natural step is to identify the appropriate ARMA model for inflation. As Campbell and Mankiw (1987) describe, there is a difficulty in estimating the parameters of ARMA processes with moving average roots close to unity. Following their recommendation, a set of ARMA models has been estimated using the Kalman filtering algorithm described in Harvey (1981). All of these models are of the form

$$
A(L) \pi_{t}=B(L) \epsilon_{t},
$$

where, $\pi$ is inflation, $A(L)$ and $B(L)$ are lag polynomials of order $p$ and $q$ respectively, and $\epsilon$ is a Gaussian white noise error term.

Table 3 reports values of the likelihood function for ARMA(p,q) models up to order $(2,2)$ using quarterly consumer price data over sample periods beginning in 1919 and ending either

\footnotetext{
quarter.

'It is important to note that differencing the data in no way biases the conclusions about persistence of inflation or deflation. As Campbell and Mankiw (1987) discuss in detail, modeling the first difference of a time series as a stationary ARMA process leaves open the question of whether the level is a stationary process. This is not to say that the results would be the same if the ARMA models where estimated in levels. The assumption that the $\log$ of the price level is an $\mathrm{AR}(2)$, for example, would imply that the price level is reverting to some mean level. This has the rather dramatic implication that the more unanticipated defiation there is, the more infiation is expected.
} 
Table 3: Model Selection Criteria: Quarterly Inflation in Consumer Prices

\begin{tabular}{|c|c|c|c|}
\hline \multirow{2}{*}{$\begin{array}{c}\text { Number of } \\
\text { AR Parameters }(p)\end{array}$} & \multicolumn{3}{|c|}{ Number of MA Parameters ( $q$ ) } \\
\hline & 0 & 1 & 2 \\
\hline \multirow[b]{2}{*}{$\mathbf{0}$} & \multicolumn{3}{|c|}{1919 to 1928} \\
\hline & $\begin{array}{c}78.197 \\
(78.197) \\
{[78.197]}\end{array}$ & $\begin{array}{c}66.695 \\
(68.694) \\
{[70.358]}\end{array}$ & $\begin{array}{c}57.329 \\
(61.329) \\
{[64.656]}\end{array}$ \\
\hline 1 & $\begin{array}{c}61.493 \\
(63.493) \\
{[65.157]}\end{array}$ & $\begin{array}{c}61.429 \\
(65.429) \\
{[68.756]}\end{array}$ & $\begin{array}{c}57.046 \\
(63.046) \\
{[68.037]}\end{array}$ \\
\hline 2 & $\begin{array}{c}61.359 \\
(65.359) \\
{[68.686]}\end{array}$ & $\begin{array}{c}59.549 \\
(65.549) \\
{[70.540]}\end{array}$ & $\begin{array}{c}53.297 \\
(61.297) \\
{[67.951]}\end{array}$ \\
\hline \multirow[b]{2}{*}{0} & \multicolumn{3}{|c|}{1919 to 1940} \\
\hline & $\begin{array}{c}157.231 \\
(157.231) \\
{[157.231]}\end{array}$ & $\begin{array}{c}138.353 \\
(140.353) \\
{[142.818]}\end{array}$ & $\begin{array}{c}132.939 \\
(136.939) \\
{[141.871]}\end{array}$ \\
\hline 1 & $\begin{array}{c}132.216 \\
(134.216) \\
{[136.682]}\end{array}$ & $\begin{array}{c}132.094 \\
(136.094) \\
{[141.026]}\end{array}$ & $\begin{array}{c}132.043 \\
(138.043) \\
{[145.441]}\end{array}$ \\
\hline 2 & $\begin{array}{c}132.080 \\
(136.080) \\
{[141.012]}\end{array}$ & $\begin{array}{c}131.774 \\
(137.774) \\
{[145.172]}\end{array}$ & $\begin{array}{c}129.528 \\
(137.528) \\
{[147.392]}\end{array}$ \\
\hline
\end{tabular}

For each model, the Table reports $-2 \ln L$, (the Akaike Criterion $=-2 \ln L+2(p+q)$ ) and [the Schwarz Criterion $=-2 \ln L+(p+q) \ln T]$. 
in 1928 or in 1940 . The table reports both the Akaike (1974) and Schwarz (1987) criteria for model selection. ${ }^{9}$

Two models stand out. For the sample ending in 1928 , the MA(2) model is not rejected by any other more general model at the $5 \%$ level using a likelihood ratio test. Furthermore, the MA(2) is chosen by the Schwarz criterion. While the Akaike criterion suggests that the $\operatorname{ARMA}(2,2)$ is superior to the $\mathrm{MA}(2)$, it is by an extremely small margin. The $\operatorname{AR}(1)$ model is clearly dominant when the long sample is used. ${ }^{10}$ Both the Akaike and the Schwarz criteria select it as the best by fairly wide margins.

The MA(2) model estimated over the 1919 to 1928 period is (inflation is measured in percent per quarter at an annual rate):

$$
\pi_{t}=0.262+\epsilon_{t}+0.586 \epsilon_{t-1}+0.708 \epsilon_{t-2}
$$

(Numbers in parentheses are asymptotic standard errors)

$$
\text { Mean of } \pi=0.263 \quad \bar{R}^{2}=.443
$$

Standard Error of the Regression $=8.195$

and the $\mathrm{AR}(1)$ model estimated over the 1919 to 1940 period is:

$$
\pi_{t}=-0.288+0.522 \pi_{t-1}+\epsilon_{t}
$$

(Numbers in parentheses are asymptotic standard errors)

$$
\text { Mean of } \pi=-0.586 \quad \bar{R}^{2}=.228
$$

Standard Error of the Regression $=8.025$.

Both of these models imply persistence in price changes at horizons of two quarters. Once a deflation begins, it is expected to continue for at least several quarters. The MA(2) model suggests that if a deflation were to begin unexpectedly, as it must be since the constant in (4) is positive, it would then be predicted to continue for two quarters at between one-half and three-quarters the initial rate. The AR(1) estimates imply that beginning with a ten

\footnotetext{
Akaike suggests minimizing $-2 \ln L+2(p+q)$, while the Schwarz criteria is to select the model that minimizes $-2 \ln L+(p+q) \ln T$, where $T$ is the sample size.

${ }^{10}$ Using quarterly data on inflation measured using the official BLS CPI from 1919 to 1938, Barsky (1987) concludes that inflation was an $\mathrm{AR}(2)$ with coefficients of 0.42 and 0.17 .
} 
percent annual rate deflation, prices would still be forecast to fall by $1 \%$ (at an annual rate) one year later. The conclusion is that inflation during the entire inter-War period was substantially serially correlated and that once a deflation started, it should have been expected to continue.

It is possible to use the ARMA estimates in (4) and (5) to generate forecasts of inflation. ${ }^{11}$ Forecasts were computed in three ways. In the first, the model was estimated using data through 1928 and then one quarter ahead forecasts were computed using all the information up to the date prior to the date of the forecast. In this procedure, the parameters of the ARMA process were fixed. This is pure out-of-sample forecasting.

In the second case, an expanding sample was used to reestimate an ARMA model using all the data up to the date prior to the date of the forecast. Then the reestimated model was used to calculate the forecast.

Finally, within sample forecasts were computed. Here the model was estimated using data through 1940 and then forecasting was done using these parameter estimates.

Figures 2 and 3 report the results of this exercise for each of the models, along with the actual values of inflation. (The vertical lines in the figure mark dates associated with specific events such as the stock market crash and various bank panics. These are described in more detail in Table 4.) For both figures, the dashed line represents actual inflation, the full within sample forecast are indicated by squares ( $\square$ ), the out of sample forecasts based on data through 1928 are marked by triangles $(\Delta)$, and the out of sample forecasts based on an expanding sample are shown by stars (*). Perhaps surprisingly, the three methods yield very similar forecasts.

As is to be expected, the AR(1) model generates smoother forecasts, and forecasts deflation more consistently. The MA(2) model shows larger, more erratic jumps. But in both cases there is a clear tendency to forecast deflation. While the forecasts imply that there was still some unanticipated deflation, the univariate models come quite a bit closer to the actual values than one might have thought.

\footnotetext{
${ }^{11}$ The forecasts are computed using the difference equation described in Chapter 5 of Box and Jenkins (1976) using 100 backcasted residuals. The TSP procedure BJFRCST was used with the default settings.
} 


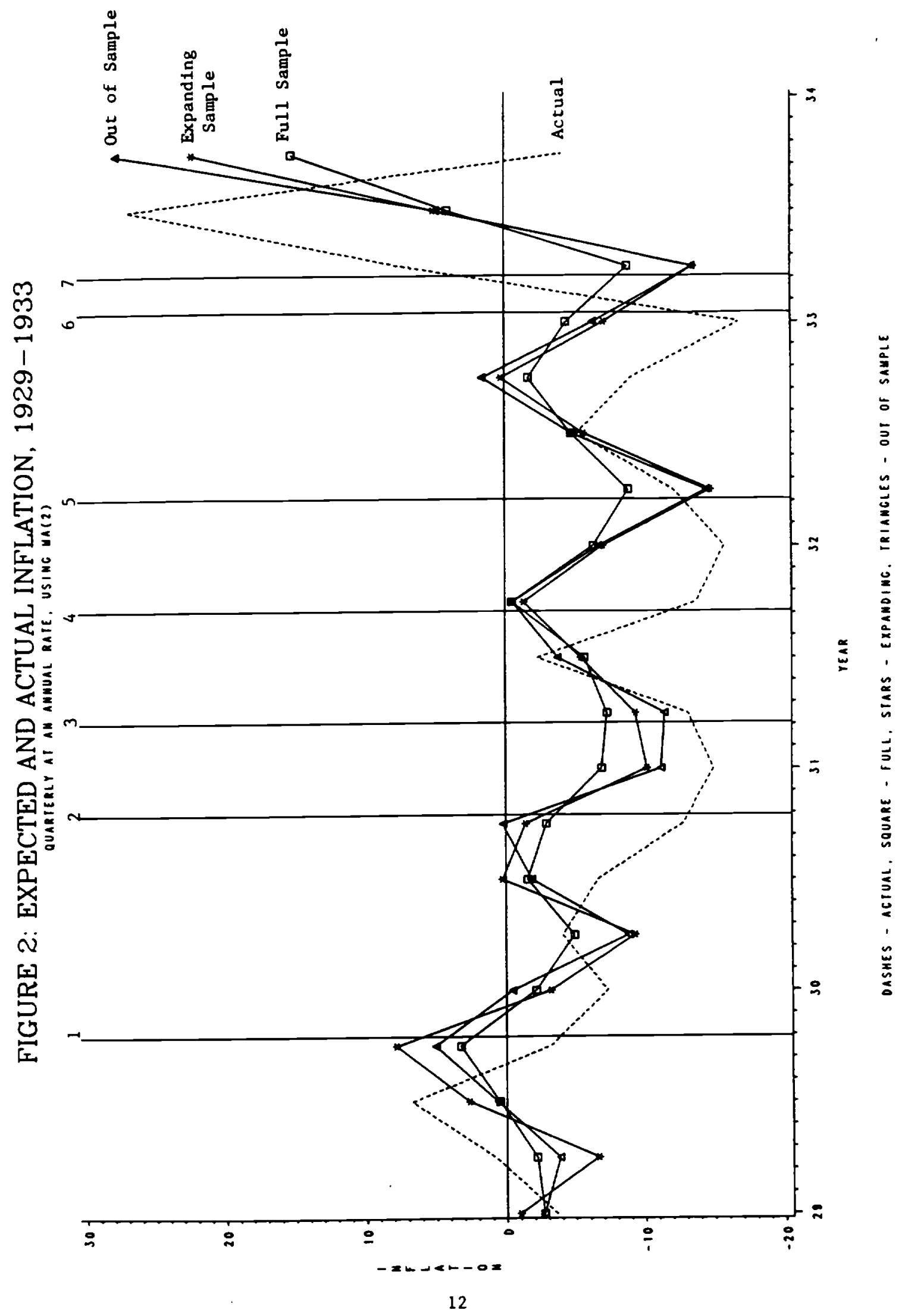




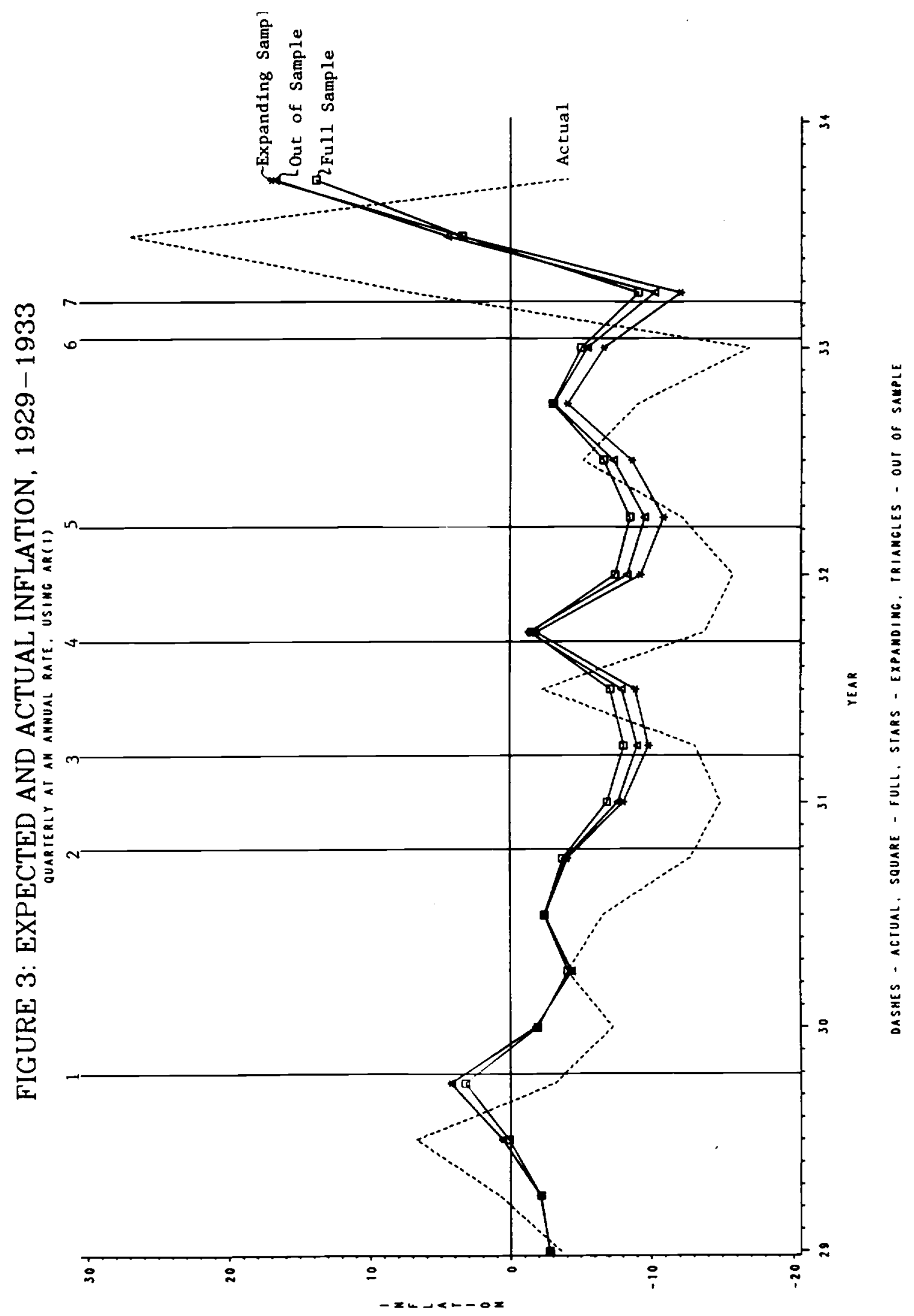




\section{Measuring Expected Inflation from Interest Rates}

In addition to studying the expectations implied by the univariate inflation process, it is also possible to obtain measures of anticipated price changes from data on interest rates. This section employs a procedure first suggested by Mishkin (1981) for dividing information in the nominal interest rate into the component that represents the ex ante real interest rate and the component that represents expected inflation.

Mishkin's technique has several advantages over the univariate procedure of Section 3. First, it allows the use of additional information. Estimates of expected inflation are based not only on the behavior of the price level, but also on movements in interest rates and other macroeconomic variables such as money growth. Furthermore, estimates of expected inflation (or deflation) that are constructed from interest rate data are not sensitive to assumptions about whether or not the price level is stationary. All that is required is the extremely plausible assumption that the real interest rate is stationary. Given the difficulty inherent in testing for a unit root in the price level, this technique provides results that are complementary to those reported in Section 3.

To understand how Mishkin's procedure works, for a $j$ period bond held from $t$ to $t+j$, define $r_{t, j}$ to be the expectation at time $t$ of the $j$ period real return on a nominally riskless bond, and $i_{t, j}$ to be the $j$ period nominal return at $t$. If $\pi_{t, j}^{e}$ is expected inflation from $t$ to $t+j$, then by the Fisher identity the ex ante real rate of interest on a $j$ period bond held to maturity is defined by

$$
r_{t, j}=i_{t, j}-\pi_{t, j}^{e}
$$

While $r_{t, j}$ is unobservable, the ex post or realized real return is not. Define eprr $r_{t, j}$ and $\pi_{t, j}$ as the realized real return and the realized inflation from $t$ to $t+j$ respectively. Then

$$
e p r r_{t, j}=i_{t, j}-\pi_{t, j}
$$

Combining (6) and (7) it is clear that $e p r r_{t, j}-r_{t, j}$, the difference between the ex ante and ex post real interest rate, is unanticipated inflation, $\left(\pi_{t, j}-\pi_{t, j}^{e}\right)$. Rational expectations implies that unanticipated inflation is always expected to be zero. So if $\Omega_{t}$ is information available at time $t$, then $\left.E\left(\pi_{t, j}-\pi_{t, j}^{e}\right) \mid \Omega_{t}\right)=0$. The econometrician, being less informed than agents in the economy, observes only a subset of $\Omega_{t}$. Using this reduced information set, $X_{t}$, an estimate of the $e x$ ante real rate of interest can be obtained by projecting $r_{t, j}$ 
on $X_{t}, P\left(r_{t, j} \mid X_{t}\right)=X_{t} \beta$. This will entail a projection error $u_{t, j}$ that is orthogonal to $X_{t}$. Making appropriate substitutions yields the regression equation

$$
\operatorname{eprr}_{t, j}=X_{t} \beta+u_{t, j}+\left(\pi_{t, j}-\pi_{t, j}^{e}\right)
$$

Since unanticipated infiation and the projection error for the real rate are both orthogonal to the components of the information set $X$, equation (8) is a standard linear regression that can be estimated using ordinary least squares. ${ }^{12}$ It is clear from the above discussion that the fitted values from this regression, $X_{t} \hat{\beta}$, are estimates of the ex ante real rate. ${ }^{13}$

Applying Mishkin's technique to Mankiw and Miron's (1985) data on three and six month time loans at New York banks, I have constructed estimates of the real interest rate for the inter-war period. The results for both maturities are virtually identical, only the three month estimates are reported below.

Choice of the variables included in the information set $X_{t}$ was dictated by several considerations discussed at length in Mishkin's work. First, the nominal interest rate was included. Then five additional variables were considered. These were the level of inflation $(\pi)$, the monetary base (MB), two measures of the stock of money (M1 and M2) and the new industrial production series recently constructed by Miron and Romer (1989). ${ }^{14}$ For each of these five variable, I began by constructing 12 month $\log$ differences. For a variable $x$, define $\Delta x_{t}=\log \left(\frac{x_{t}}{x_{t-12}}\right)$. Then, for a given variable $\left(\Delta x_{t-1}, \Delta x_{t-13}, \Delta x_{t-25}\right)$ were all added to the regression (8). That is, the information set was assumed to contain the most recently available value of the growth rate in $x$ over the previous year, as well as the growth rate lagged one and two years. After estimating the projection equation including these variables, a Wald test was performed in which the null hypothesis was that the three coefficients on the new variable were jointly different from zero. If null was rejected, the variable

\footnotetext{
${ }^{12}$ Equation (8) can be thought of as a simplified linear form of the expression for the interest rate that would arise in the model developed by Cox, Ingersoll and Ross (1985) and applied by Brown and Dybvig (1986). In their scheme, the bond yield is a linear function of the state variables, or factors. The weights on the factors depend on the parameters of the vector stochastic process that describes the state. If we assume that this process is atable, so that the weights are time invariant, and that $X_{t}$ is a set of variables describing the state at time $t$, then the $\beta$ 's are the weights. Since the purpose here is to recover the real interest rate without explicitly specifying the set of factors and their stochastic process, it is unnecessary to do more than examine the simple projection equation ( 8 ).

${ }^{13}$ As is discussed in the work by Huizinga and Mishkin (1986), when the holding period $j$ is larger than one, and overlapping data are used, the error in this regression will be a moving average of order $j$. This implies that a robust procedure must be used to estimate the standard error of $\hat{\beta}$ consistently.

16The Appendix includes a complete description of the sources. All data are seasonally unadjusted.
} 
Table 4: Chronology of Monetary Events During the Depression from Friedman and Schwartz (1963)

\begin{tabular}{l}
\hline 1 - October 1929 - Stock Market Crash \\
2 - October 1930 - First Banking Crisis \\
3 - March 1931 - Second Bank Crisis \\
4- September 1931 - Britain Leaves the Gold Standard \\
5 - April 1932 - Onset of Open Market Purchases \\
6 - January 1933 - Last Banking Crisis \\
7 - March 1933 - Bank Holiday \\
8 - January 1937 - Announcement of Final Rise in Reserve Requirement \\
9 - May 1937 - Effective Date of Reserve Requirement Increase \\
Numbers correspond to vertical lines in the Figures.
\end{tabular}

was included, if it was not, the variable was dropped. Because the interest rate data is at a monthly frequency, but for three month yields, the error term in (8) is a second order moving average. This means that a robust covariance matrix estimator must be used. ${ }^{15}$ Variables were examined in the following order: inflation, industrial production, M2, MB, and $M 1{ }^{16}$ The resulting tests yielded the specification which included inflation, M2 and the monetary base. ${ }^{17}$

Figure 4 plots the estimates of $r_{t, 3}$, the one quarter ahead ex ante real interest rate from 1919 to 1940 along with five percent confidence intervals. The vertical lines on this and all subsequent figures represent events related to the Friedman and Schwartz chronology in Table 4 .

The most striking feature of Figure 4 is the height of the real interest rate estimates throughout the latter half of the 1920s and the early 1930s. While it moves substantially, it is consistently between 5 and 10 percent. These high real rates persist until the bank

\footnotetext{
${ }^{15}$ The estimates here employ the simple moment estimator suggested by Hansen and Hodrick (1980), unless it is not positive definite in which case the Newey and West (1987) estimalor is used.

${ }^{16}$ The actual statistical properties of such a sequential testing procedure are not known. The order in which the variables were tested does make a small difference. For example, if $M 2$ is entered before in fiation, inflation will not have much added explanatory power. Fortunately, the results for the estimated levels of the real interest rate and expected inflation are robust to these changes.

${ }^{17}$ In the presence of overlapping data, an additional check on the specification is to see if the residual autocorrelations beyond two are equal to zero. Cumby and Huizinga (1989) have recently developed a test for this hypothesis. The value of their test statistic testing the null that the third through eighth autocorrelations in the residual in the regression (8) are zero is 7.79 . This statistic is distributed as Chisquared with six degrees of freedom under the null. The $10 \%$ critical value for a $\chi^{2}(6)$ is 10.65 , implying that the model meets the desired criterion.
} 


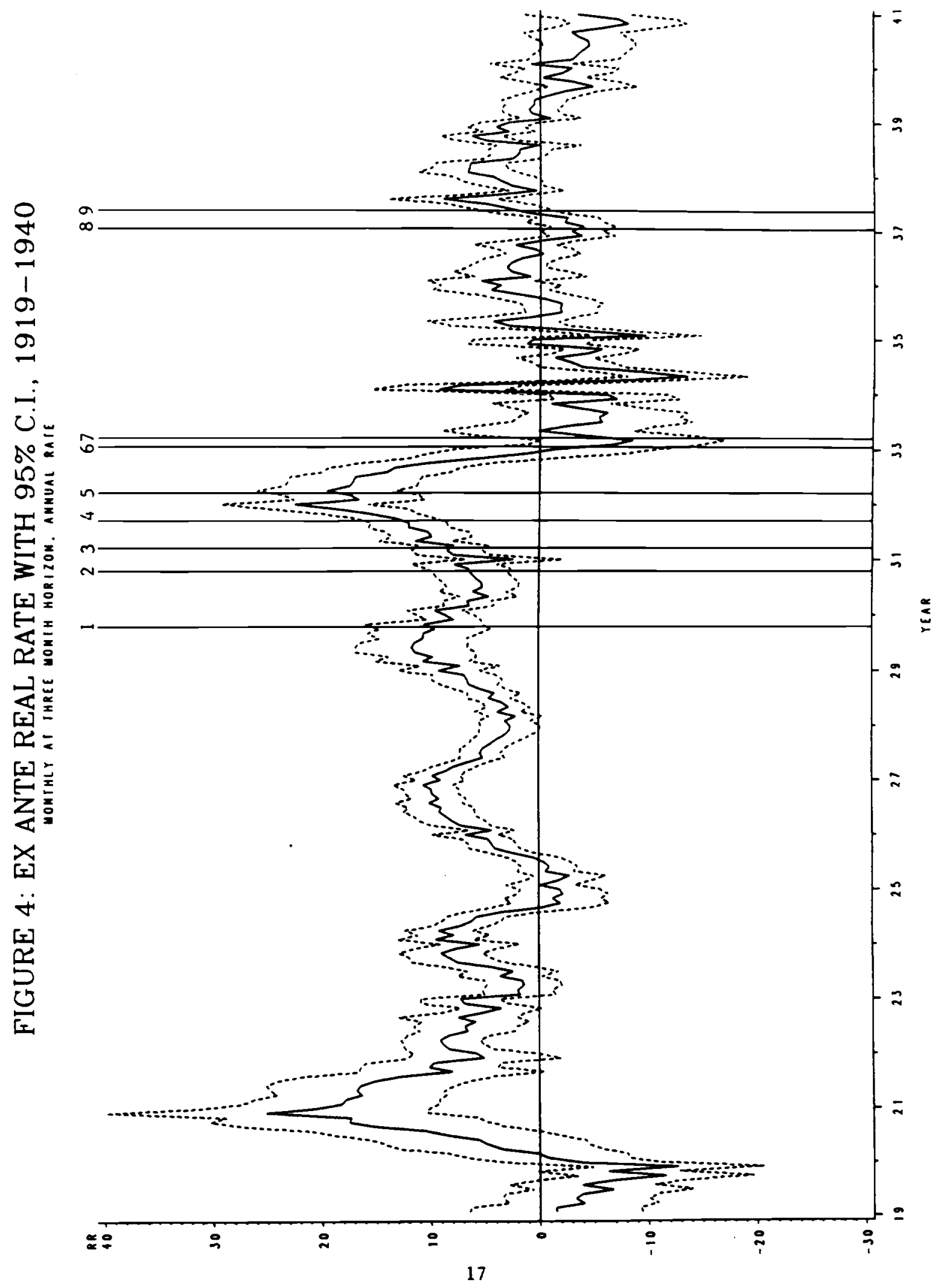


holiday in 1933 (the vertical line labeled 7), when the estimates show a sharp drop to fairly sizable negative levels. Given that nominal interest rates declined steadily from October 1929 to February 1933, with only a brief rise in late 1931 and early 1932, this implies that deflation was actually anticipated during 1930 and 1931 .

Figure 5 plots expected inflation implied by the real interest rate estimates in Figure 4. Once again, $5 \%$ confidence intervals are included. Beyond supplying clear support for the proposition that the 1930-32 deflation was anticipated, these are relevant to two on going debates about the nature of the Depression. The first pertains to the Lucas and Rapping (1969) claim that unanticipated deflation led to intertemporal substitution, which then explains the low level of employment during the 1930s. Clearly these estimates do not support their position.

The primary debate over the causes of the Great Depression is Friedman and Schwartz vs. Temin (1976). The most recent version of this is the appears in Brunner (1981). As Schwartz (1981) points out, the monetary hypothesis requires that real interest rates be high from 1930 through 1932. This is clearly supported by the results presented Figure 4, where real interest rates on three month time loans exceed $5 \%$ throughout the period, and reached a peak in excess of $20 \%$ in early 1932 . Finally, the fact that real interest rates were high beginning in 1927 confirms Hamilton's (1987) conclusion that tight monetary policy initiated the Depression.

It is useful to compare the results from the univariate models of Section 3, the MA(2) and $A R(1)$, with those obtained from the interest rate data. Table 5 presents the estimates of expected inflation using six different procedures. For each of the three models, the table contains two estimates of expected inflation. The first are the full within sample forecasts, and the second are the expanding out of sample forecasts. All the estimates are for three month periods, measured at annual rates. In addition, the table reports the actual, ex post level of inflation.

The expanding sample estimates all have an advantage over the within sample fitted values. Any procedure that relies on least squares, including the Mishkin technique and simple estimates of autoregressive models, has major shortcomings that might lead one to be skeptical of the results based on full sample estimation. In particular, the fitted values from any OLS regression tend to follow the raw data rather closely - estimates of ex ante values will look very much like ex post realizations. This makes inferences about expectations from 


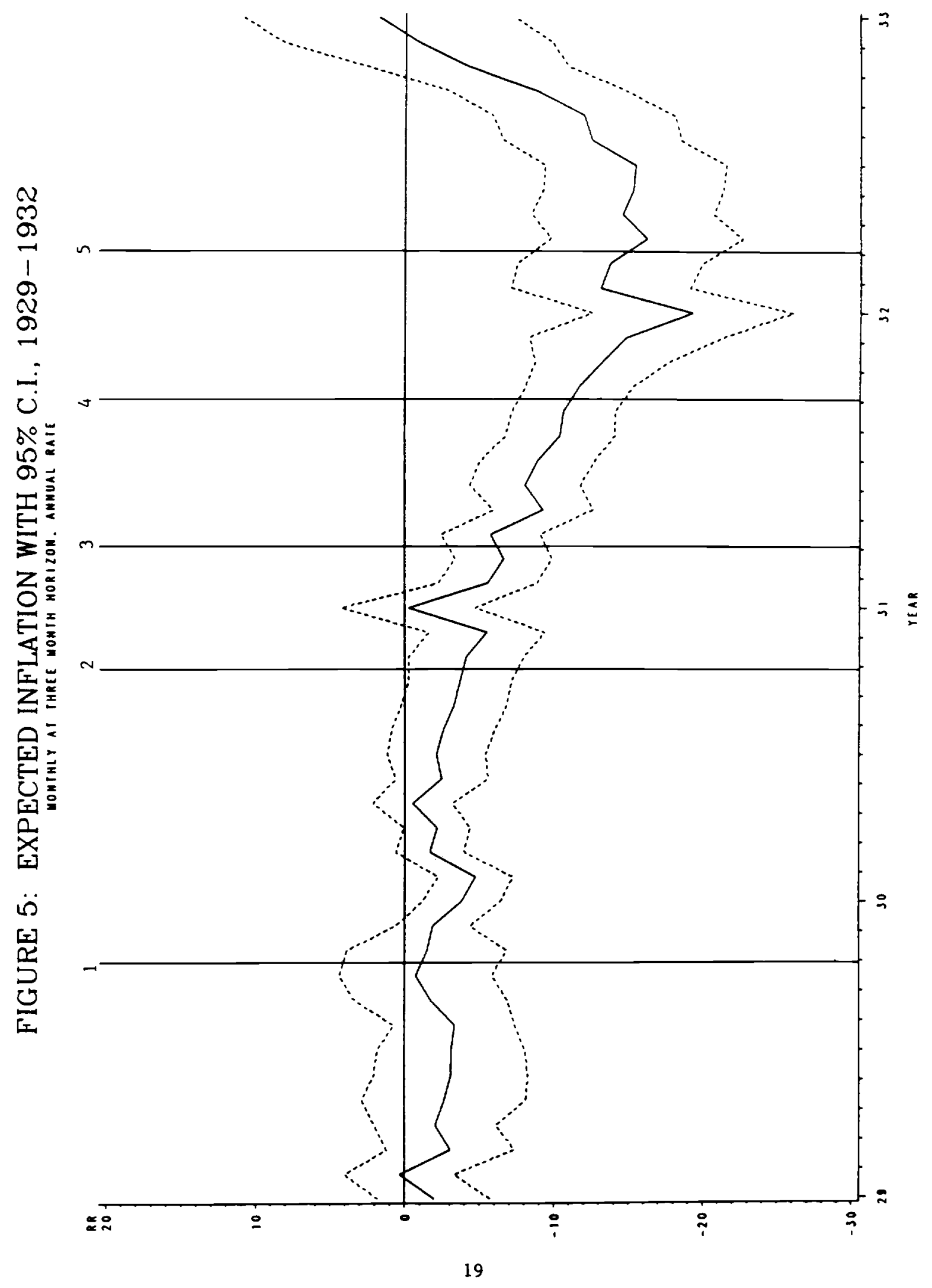


Table 5: Table Comparing Expected and Actual Inflation All estimates are for one quarter at annual rates

\begin{tabular}{||c|r|rc|rc|rc||}
\hline \hline & & \multicolumn{2}{|c|}{ MA(2) } & \multicolumn{2}{c|}{ AR(1) } & \multicolumn{2}{c||}{ INTEREST RATE } \\
\hline Date & Actual & \multicolumn{1}{|c|}{ Full } & Expanding & \multicolumn{1}{|c|}{ Full } & Expanding & \multicolumn{1}{c|}{ Full } & Expanding \\
\hline $29: 01$ & -3.60 & -2.68 & -0.95 & -2.77 & -2.80 & -1.95 & -0.43 \\
$29: 02$ & 0.80 & -2.17 & -6.61 & -2.17 & -2.14 & -2.04 & -4.20 \\
$29: 03$ & 6.75 & 0.51 & 2.67 & 0.13 & 0.57 & -3.12 & -8.37 \\
$29: 04$ & -3.16 & 3.28 & 7.86 & 3.24 & 4.28 & -0.73 & 0.10 \\
\hline $30: 01$ & -7.29 & -2.14 & -3.20 & -1.94 & -1.79 & -3.77 & -5.32 \\
$30: 02$ & -4.06 & -4.91 & -9.29 & -4.10 & -4.38 & -2.13 & -3.99 \\
$30: 03$ & -6.59 & -1.55 & 0.27 & -2.41 & -2.46 & -2.11 & -3.98 \\
$30: 04$ & -12.74 & -2.89 & -1.39 & -3.73 & -4.07 & -3.69 & -3.29 \\
\hline $31: 01$ & -14.94 & -6.89 & -10.16 & -6.94 & -8.09 & -0.02 & 1.04 \\
$31: 02$ & -13.12 & -7.28 & -9.33 & -8.09 & -9.85 & -5.76 & -7.77 \\
$31: 03$ & -2.31 & -5.69 & -5.38 & -7.14 & -8.91 & -8.89 & -12.14 \\
$31: 04$ & -13.74 & -0.46 & -1.32 & -1.49 & -1.85 & -11.68 & -10.29 \\
\hline $32: 01$ & -15.72 & -6.34 & -7.01 & -7.46 & -9.25 & -19.27 & -18.08 \\
$32: 02$ & -12.13 & -8.87 & -14.78 & -8.49 & -10.86 & -16.18 & -12.96 \\
$32: 03$ & -5.17 & -4.75 & -5.65 & -6.62 & -8.62 & -15.41 & -12.20 \\
$32: 04$ & -9.04 & -1.67 & 0.30 & -2.98 & -4.03 & -8.84 & -1.21 \\
\hline $33: 01$ & -16.83 & -4.40 & -7.09 & -5.01 & -6.63 & 1.76 & 22.07 \\
$33: 02$ & 7.15 & -8.82 & -13.60 & -9.08 & -12.05 & 7.17 & 12.39 \\
$33: 03$ & 26.96 & 4.08 & 5.09 & 3.44 & 3.55 & 6.60 & -4.04 \\
$33: 04$ & -4.10 & 15.21 & 22.33 & 13.79 & 16.95 & 4.25 & 4.47 \\
\hline \hline
\end{tabular}

The MA(2) and AR(1) estimates are the values plotted in Figures 2 and 3. The 'Interest Rate' estimates are constructed from equation (8). 
within sample fitted values suspect. ${ }^{18}$

Out of sample forecasting is a natural way to address this concern. The expanding sample estimates compute forecasts using data that was available at the time the forecast needed to be made. To understand the procedure, take a simple example. In every case, the estimate for the first quarter of 1930 was obtained by estimating the model through the end of 1929 and then forecasting the beginning of 1930 . The forecasts use only information through the end of 1929 .

The important feature of Table 5 is that all the estimates show the same basic properties. By the end of 1929 deflation was anticipated, although expectations were that it would be a fairly moderate -2 to -3 percent. But things got progressively worse, and expectations of deflation clearly persisted. For the first three quarters of 1931 , these methods all generated expectations of deflation that exceed $-5 \%$. Furthermore, this conclusion that the deflation was anticipated is robust to changes in the estimation procedure.

All of the evidence presented above suggests that the deflation of 1930-32 was anticipated, at horizons of three to six months. The historical record suggests that deflation was within the experience of contemporary agents, while statistical analysis of data on inflation and interest rates shows that the deflation was readily forecastable. The substantial persistence in the inflation process is the driving force behind these results.

\section{Comparison with Previous Work}

The results using both univariate prices and interest rates differ dramatically from those reported by Hamilton (1987) and by Dominguez, Fair and Shapiro (1988). Both of these papers conclude that the deflation was unanticipated. It is worth commenting on the reasons for these differences.

Using data from commodity futures markets, Hamilton (1987) concludes that the deflation of 1930-32 was unanticipated. Hamilton measures expectations of future inflation by looking at the difference between the current spot price and the futures price, six months ahead, for a number of storeable commodities including cotton, wheat, corn and oats.

There are at least three reasons to be skeptical of his results. First, when considering

\footnotetext{
${ }^{18}$ In essence, the agents in the economy have to know the true model before the data have been produced for an econometrician to estimate it. During a period like the 1930 s this seems like a rather large leap of faith.
} 
commodity futures markets it is important to keep in mind the existence of physical stocks. These stocks are assets whose risk adjusted nominal return must equal that of other assets. $A$ bond is in this set of alternatives and since, except for in exceptional circumstances described in Cecchetti (1988), the nominal interest rate can never be negative, the price of the stored commodity can never be expected to fall. ${ }^{19}$ Second, it appears from work by Mishkin (1987) that anticipated changes in commodity prices, as represented by futures contract prices, are a poor measure of expectations of aggregate price movements. Instead, the information contained in the futures represent anticipated relative price movements. ${ }^{20}$

The final reason to doubt Hamilton's conclusions comes from examining the nature of government intervention in the futures markets during the early 1930s. Peck (1976) describes how from 1929 to 1933 the Federal Farm Board in an attempt to stabilize agricultural commodities prices, traded futures contracts. While its goal was the stabilization of the all agricultural commodity prices, the focus of the Farm Board's activity was on the wheat and cotton markets. Peck documents that during 1930 and 1931, the Farm Board, through the Grain Stabilization Corporation, held large open positions in the wheat futures market. During late 1930 and early 1931, the Farm Board's positions often comprised over half of the open interest in wheat futures in the Chicago, Kansas City, and Minneapolis markets. In fact, in Minneapolis, the Farm Board owned 93\% of the open interest in wheat futures during March 1931. Furthermore, by the end of the 1930-31 crop year, the government owned outright more than 250 million bushels of wheat, or nearly three quarters of the 344 million bushels produced during that year.

Peck's study focuses on wheat futures held by the Federal Farm Board through the Grain Stabilization Corporation, but she notes that other federal agencies were participating in futures markets at the same time. The clear goal of government policy was to keep the prices of agricultural commodities from falling and one of the main methods for doing so was to participate in the futures market. Given the nature and magnitude of government intervention in the commodity futures markets between 1929 and 1933, it is difficult to see

\footnotetext{
${ }^{19}$ There are several caveats to this simple argument. In the presence of a convenience yield, the commodity price can fall at that rate. Furthermore, the price can be expected to drop at the harvest date, at which point the stock of the previous year will be nearly exhausted.

${ }^{20}$ Mishkin examines Hamilton's procedure by comparing it to his own method of extracting estimates of expected inflation from ex post real interest rates. (See Section 4 below.) He concludes that $99 \%$ of the movement in the own commodity real rates computed from futures market data is a consequence of anticipated relative price movements, while only $1 \%$ is the result of movements in the aggregate real interest rate.
} 
how prices in these markets can be used to infer the beliefs of private agents in the economy at the time.

By contrast, Dominguez, Fair and Shapiro (1988) examine the joint time series process of prices and industrial production, interest rates, stock prices and the money stock, in addition to indices constructed by Irving Fisher and by the Harvard Economic Service. Using a vector autoregression that includes the price level they conclude that defiation was unanticipated. The critical difference between their results and those reported here that they presume the price level to be stationary, while I do not. If the price level is stationary and follows an AR process, then unanticipated deflation will ultimately lead to anticipated inflation. This means that the prolonged deflation of 1930-32 would have been more and more unanticipated. All of the results in Sections 3 and 4 suggest that this is implausible.

\section{Conclusion}

The purpose of this paper has been to show that the deflation of 1930-32 could have been anticipated. Simple models of price expectations, based on either univariate time series models or on the information contained in interest rates, suggest that the persistence in the inflation process would have led agents to believe that the deflation would continue once it began. This result suggests simple debt-defiation theories for the propagation of the Depression must rely on the failure of agents to anticipate deflation several years in advance, not several quarters in advance. To show that debt-deflation was an important part of the contraction of the early 1930s it is important to document the accumulation of substantial medium and long term debt prior to $1929 .{ }^{21}$

While answering one question, these conclusions naturally lead to a new question. If the debt-deflation hypothesis is suspect, then how can we explain the severe contraction of 1930-32? It seems likely that the deflation was an important characteristic of this period. The observation that the deflation of 1930-32 could have anticipated suggests a new interpretation of the Great Depression that concentrates on the consequences of anticipated deflation. Future research will examine the implications of a deflation that is so severe that it causes the nominal interest rate to hit its zero constraint. This has two immediate

\footnotetext{
${ }^{21}$ The results in Bordo and Ellson (1985) suggest a radical interpretation. They infer that depletion of the gold stock should have led to deflation beginning anticipated throughout the $1920 \mathrm{~s}$. If they are correct, it would be even more difficult to make sense of the debt-deflation story.
} 
implications. First, it drives up the real return on money and will lead to negative net investment. Second, when the zero nominal interest rate constraint binds, the opportunity cost of money to becomes negative, leading to a change in the nature of currency. The natural response is a flight to quality, in this case cash or other government liabilities, that puts the banking system at risk. 


\section{Data Appendix}

This appendix describes the data used in the paper.

\section{Consumer Prices:}

The monthly consumer price series was constructed by splicing together two series. From January 1913 to December 1919 the raw data is the U.S. Department of Labor, Bureau of Labor Statistics Consumer Price Index. From January 1920 to December 1940 the raw data are the National Industrial Conference Board all items consumers' price index published in Sayre (1948) Table 1. It does not appear that the BLS collected and published at monthly series on the prices of consumer goods during the 1920's and 1930's. The all items CPI data that are currently available for this period seem to have been created from data sampled at a lower frequency and then interpolated using some component series. The quarter consumer price series is then constructed by taking the last observation of each quarter of the monthly series.

The annual consumer price series is constructed by splicing the annual Federal Reserve Bank of New York 'Estimated Cost of Living' index to the BLS CPI.

\section{Wholesale Prices:}

Data on wholesale prices were constructed by splicing data from Warren and Pearson (1935) Table 1 to the all commodities wholesale price index published by the BLS beginning in January of 1913 .

\section{GNP Deflator:}

Prior to 1929, data were taken from Romer (1988). Beginning in 1929, the data are from the Bureau of Economic Analysis, National Income and Product Accounts.

\section{Money Stock:}

All data on money are from Friedman and Schwartz (1963) Appendix A. Data on the M1 and M2 are taken Table A-1, and data on the monetary base are from Appendix A, Table A-2.

\section{Interest Rates:}

Interest rate data is three month time loan rates at New York banks. The data were collected by Mankiw and Miron (1985).

\section{Industrial Production:}

The new series collected by Miron and Romer (1989) was used. The data are monthly, seasonally unadjusted and provide a consistent monthly series beginning in January 1884 . 


\section{References}

Akaike, H., 'A New Look at Statistical Model Identification,' IEEE Transactions on Automatic Control, AC-19 (1974): 716-723.

Barsky, Robert B., 'The Fisher Hypothesis and the Forecastability and Persistence of Inflation,' Journal of Monetary Economics 19 (January 1987): 3-24.

Bernanke, Ben S. and Mark Gertler, 'Agency Costs, Net Worth, and Business Fluctuations,' American Economic Review 79 (March 1989): 14-31.

and , 'Financial Fragility and Economic Performance,' N.B.E.R. Working Paper No. 2318, July 1987.

Bordo, Michael D. and Richard W. Ellson, 'A Model of the Classical Gold Standard with Depletion,' Journal of Monetary Economics 16 (July 1985): 109-120.

Box, George E. P. and Gwilym M. Jenkins. Time Series Analysis: Forecasting and Control. San Francisco: Holden-Day, Inc., 1976.

Brown, Stephen and Philip Dybvig, 'The Empirical Implications of the Cox, Ingersoll and Ross Theory of the Term Structure of Interest Rates,' Journal of Finance 41 (July 1986): $617-632$.

Brunner, Karl, ed. The Great Depression Revisited. Boston: Martinus Nijhoff, 1981.

Campbell, John Y. and N. Gregory Mankiw, 'Are Output Fluctuations Transitory?' Quarterly Journal of Economics 102 (November 1987): 857-880.

Cecchetti, Stephen G., 'The Case of the Negative Nominal Interest Rates: New Estimates of the Term Structure of Interest Rates During the Great Depression,' Journal of Political Economy 96 (December 1988): 1111-1141. 1988 .

Cox, John C., Jonathan E. Ingersoll and Stephen A. Ross, 'A Theory of the Term Structure of Interest Rates,' Econometrica 53 (March 1985): 385-408.

Cumby, Robert E. and John Huizinga, 'Testing the Autocorrelation Structure of Disturbances in Ordinary Least Squares and Instrumental Variables Regressions,' Stern School of Business, New York University, mimeo, January 1989.

Dickey, David A. and Wayne A. Fuller, 'Likelihood Ratio Statistics for Autoregressive Time Series with a Unit Root,' Econometrica 49 (July 1981): 1057-1072.

Dominguez, Kathryn M., Ray C. Fair and Matthew D. Shapiro, 'Forecasting the Depression: Harvard versus Yale,' American Economic Review 78 (September 1988): 595-612.

Fisher, Irving, 'The Debt-Deflation Theory of the Great Depression,' Econometrica 1 (October 1933): 337-357.

Fuller, Wayne A. Introduction to Statistical Time Series. New York: John Wiley and Sons, 1976. 
Friedman, Milton and Anna Schwartz. A Monetary History of the United States, 18671960. Princeton: Princeton University Press, 1963.

Hamilton, James D. , 'Monetary Factors in the Great Depression,' Journal of Monetary Economics 19 (March 1987): 145-169.

Hansen, Lars Peter and Robert Hodrick, 'Forward Exchange Rates as Optimal Predictors of Future Spot Rates,' Journal of Political Economy 88 (1980): 829-853.

Harvey, Andrew C. Time Series Models. Oxford: Philip Allan, 1981.

Huizinga, John and Frederic S. Mishkin, 'Monetary Policy Regime Shifts and the Unusual Behavior of Real Interest Rates,' in Karl Brunner and A. Meltzer, eds., The National Bureau Method, International Capital Mobility and Other Essays, Carnegie-Rochester Conference on Public Policy, vol. 24, Spring 1986.

Lucas, Robert E. Jr. and Leonard A. Rapping,'Real Wages, Employment and Inflation,' Journal of Political Economy 77 (September/October 1969): 721-754.

Mankiw, N. Gregory and Jeffrey A. Miron, 'The Changing Behavior of the Term Structure of Interest Rates,' N.B.E.R. Working Paper 1669, July 1985.

Miron, Jeffrey A. and Christina D. Romer, 'A New Monthly Index of Industrial Production, 1884-1940,' mimeo, U.C. Berkeley, September 1989.

Mishkin, Frederic, 'The Real Interest Rate: An Empirical Investigation' in K. Brunner and A. Meltzer, eds. The Costs and Consequences of Inflation, Carnegie Rochester Conference Series on Public Policy, vol. 15, 1981 151-200.

, 'Can Futures Market Data Be Used to Understand the Behavior of Real Interest Rates?' N.B.E.R. Working Paper No. 2400, October 1987.

Newey, Whitney K. and Kenneth D. West, 'A Simple, Positive Definite, Heteroskedasticity and Autocorrelation Consistent Covariance Matrix,' Econometrica 55, May 1987, 703708.

Peck, Anne E., 'The Futures Trading Experience of the Federal Farm Board,' in Chicago Board of Trade, Future Trading Seminar Proceedings Chicago, Ill.: Chicago Board of Trade, 1976.

Romer, Christina D., 'Gross National Product, 1909-1928: Existing Estimates, New Estimates, and New Interpretations of World War I and its Aftermath,' Journal of Monetary Economics 22 (July 1988): 91-116.

Said, S. E. and D. A. Dickey, 'Testing for Unit Roots in Autoregressive-Moving Average Models of Unknown Order,' Biometrika 71 (1985) 599-607.

Sayre, Robert A. Consumers' Prices: 1914-19/8. New York: National Industrial Conference Board, 1948.

Schwartz, Anna J., 'Understanding 1929-1933,' in K. Brunner, ed. The Great Depression Revisited, Boston: Martinus Nijhoff Publishing, 1981.

Schwarz, G., 'Estimating the Dimension of A Model,' Annals of Mathematical Statistics 6 (1978): 461-4. 
Schwert, G. William, 'Tests for Unit Roots: A Monte Carlo Investigation,' N.B.E.R. Technical Working Paper No. 73, December 1988.

Temin, Peter. Did Monetary Forces Cause the Great Depression? New York: W.W. Norton, 1976.

Warren, George F., and Frank A. Pearson. Gold and Prices. New York: John Wiley and Sons, 1935. 